\title{
CANCER VACCINES: BETWEEN THE IDEA AND THE REALITY
}

\section{Olivera J. Finn}

Whether vaccines are designed to prepare the immune system for the encounter with a pathogen or with cancer, certain common challenges need to be faced, such as what antigen and what adjuvant to use, what type of immune response to generate and how to make it long lasting. Cancer, additionally, presents several unique hurdles. Cancer vaccines must overcome immune suppression exerted by the tumour, by previous therapy or by the effects of advanced age of the patient. If used for cancer prevention, vaccines must elicit effective long-term memory without the potential of causing autoimmunity. This article addresses the common and the unique challenges to cancer vaccines and the progress that has been made in meeting them. Considering how refractory cancer has been to standard therapy, efforts to achieve immune control of this disease are well justified.

Between the idea

And the reality

Between the motion

And the act

Falls the Shadow.

T. S. Eliot

Edward Jenner's landmark publication in 1798 (REF. 1) that describes a vaccine against small pox, is considered to be the official beginning of the science of immunology. Immunology has since then made many contributions to scientific enterprise and to many different scientific disciplines, including genetics, molecular biology and cellular biology. The most important contribution of immunology to improving the quality of human life is the development of vaccines.

Twenty-six infectious diseases are preventable through vaccination, at present. In spite of two centuries of vaccine development, however, there are still several parasitic, bacterial and viral diseases, such as Chagas, malaria, tuberculosis and hepatitis C, that have so far eluded protection through vaccines. Modern times have also brought new diseases, such as HIV and cancer. The successes from the past and an ever-increasing level in our understanding of basic immune mechanisms and the ability to manipulate them, predict future victories ${ }^{2}$.

\section{Challenges facing all vaccines}

In addition to taking on the challenge to design better vaccines against infectious diseases, immunologists are exploring the possibility of using vaccines against other ailments that involve the immune system. Most notable efforts are directed to developing vaccines for cancer and certain autoimmune diseases. Vaccines that are designed to prepare the immune system for encounter with either infectious pathogens or with cancer or mediators of autoimmunity, all face certain common challenges that are reviewed here.

Choosing the right antigen. Traditionally, successful vaccines have consisted of live attenuated pathogens. Although effective at the population level, these vaccines have a small, but significant, risk of activation that can cause disease or other harmful side effects. On the basis of the successes of attenuated pathogen vaccines and owing to the initial lack of defined tumour antigens, the first cancer vaccines were composed of whole tumour cells that were previously irradiated or otherwise inactivated ${ }^{3}$. In mouse models, this immunization strategy was successful, producing tumour-specific immune responses and rejection of a tumour challenge. These early vaccines used either tumour-cell lines that had accumulated many mutations through numerous passages in vivo or in vitro 
and were, therefore, highly immunogenic, or carcinogeninduced tumours with unique mutations that function as highly stimulatory antigens. As this work expanded to spontaneous tumours that better mimicked human tumours, whole tumour cells proved to be non-immunogenic or weakly immunogenic. Along with these experiments, immunologists were deciphering the exact requirements for antigen specific T-cell activation. They discovered that, in addition to receiving a signal through the T-cell receptor (TCR), naive $T$ cells required additional co-stimulatory signals. This prompted the use of vaccines that were composed of gene-modified tumour cells that expressed various co-stimulatory molecules and/or cytokines, which made them markedly more immunogenic in animal models. Successful animal studies encouraged several clinical trials of cancer vaccines on the basis of gene-modified autologous or allogeneic human tumour cells ${ }^{4,5}$.

Just as vaccines that are based on whole pathogens are associated with risks of reactivation and development of disease, whole tumour-cell vaccines present significant health risks. The most serious is the potential for causing autoimmunity. Immature dendritic cells (DCs) that reside in tissues take up and process dying cells and self antigens, but in the absence of strong activating signals, such as those given by pathogens, no immune response to these antigens is generated. To elicit strong immunity, the tumour-cell vaccine must include substances that activate DCs. In the case of whole tumour cells, however, it should be expected that in addition to presenting tumour-specific antigens, activated DCs would prime immunity to many other antigens (autoantigens) that are otherwise subject to peripheral tolerance. This is not a hypothetical case evidence for autoimmune reactions following vaccination has accumulated from work in animal models, as well as clinical trials ${ }^{6-9}$.

The use of whole tumour cells or complex mixtures of tumour-derived material undermines one unique advantage that immunotherapy has over other forms of therapy - that is, specificity. The immune response can recognize epitopes that are expressed by tumour cells and target those cells for destruction without harming normal cells. To take advantage of specificity, the past two decades in tumour immunology have been characterized by considerable effort into the discovery of tumour antigens. Many such antigens were discovered and cancer vaccines based on these antigens have been shown in pre-clinical studies to elicit tumour-specific immunity and establish long-term memory without autoimmunity ${ }^{10-15}$. For breast cancer, for example, vaccines composed of epitopes that are derived from mucin 1 (REF. 16), HER2/NEU ${ }^{17}$, melanoma-associated antigen 3 (MAGE3) or other members of the MAGE gene family ${ }^{18}$, mammaglobin ${ }^{19}$ or carcinoembryonic antigen (CEA) ${ }^{20}$ have been extensively studied and shown to be immunogenic without causing autoimmunity. Several other antigens under investigation at present will soon be added to the panel of breast-tumour antigens, such as cyclin B1 (REF. 21), or one of many cancer-germ-cell antigens that are specifically found in breast tumours ${ }^{22}$. Similarly, there are a large number of antigens available for melanoma vaccines. Extensive studies have been carried out with them in animal models and in clinical trials ${ }^{23}$. In addition to being well explored and understood, many of these antigens are SHARED TUMOUR ANTIGENS. Vaccines that are composed of these antigens can be developed for use in a large number of patients.

Recently, however, in spite of the availability of well-defined tumour antigens, development in the cancer-vaccine field has focused again on the use of whole tumour cells or whole-cell lysates as antigens. The reason being that these complex mixtures will contain UNIQUE TUMOUR ANTIGENS that are expressed only by an individual tumour that, by analogy to unique antigens of mouse carcinogen-induced tumours might be more immunogenic and promote a better antitumour immune response ${ }^{24}$. Experiments carried out in mice transgenic for shared tumour antigens have shown that these antigens can elicit equally strong antitumour immunity and tumour rejection ${ }^{12,25-27}$. Furthermore, it has been shown in animal models and in some clinical trials, that a vaccine based on a shared antigen, which elicits an antitumour response, can elicit responses to other antigens on that tumour through a process known as EPITOPE SPREADING ${ }^{17,28,29}$ or 'provoked immunity'14.

The more disturbing reason that might be driving the field away from vaccines that are based on defined tumour antigens is dissatisfaction with the results that have been achieved in the clinic so far. Before we underestimate the potential of defined tumour antigen-based vaccines and go back to undefined tumour mixtures that have the potential for autoimmunity, it must be remembered that antigen-based vaccines have been successful in animal models in which they have been tested almost exclusively in tumour prevention. These vaccines have not yet been given a chance to replicate that success in humans, because they are being tested exclusively as therapeutic agents in advanced disease and often after the failure of standard therapy.

Choosing the right adjuvant. ADJUVANTS are crucial components of all cancer vaccines whether they are composed of whole cells, defined proteins or peptides. Even though, at present, there are only two adjuvants worldwide that are approved for clinical use aluminum-based salts (alum) and a squalene-oilwater emulsion (MF59) - many other substances that increase the immunogenicity of vaccines have been tested and proven to be effective in animal models and humans. Many new adjuvants are molecules of known function and, therefore, the mechanisms of their adjuvant action are better understood. Adjuvants can activate antigen-presenting cells (APCs) to stimulate $\mathrm{T}$ cells more efficiently, activate natural killer (NK) cells or other cells of the innate system to produce cytokines or promote the survival of antigen-specific T cells. 
T HELPER $1 / 2$ CELLS

$\mathrm{T}_{H} 1 / \mathrm{T}_{H} 2$ cells. Two subsets of

activated $\mathrm{CD} 4^{+} \mathrm{T}$ cells that can

be distinguished by the

cytokines they produce. $T_{H} 1$ cells

produce interferon- $\gamma$,

lymphotoxin and tumour-

necrosis factor, and enhance cell-

mediated immunity. $\mathrm{T}_{\mathrm{H}} 2$ cells

produce interleukin-4 (IL-4),

IL-5 and IL-13, and support

humoral immunity.
Cytokines, such as interleukin-2 (IL-2), granulocytemacrophage colony-stimulating factor (GM-CSF), IL-12, IL-4 and several others, have been used as adjuvants in cancer vaccines ${ }^{30}$. Bacterial products have also been used for many years as effective adjuvants. The two best known are lipopolysaccharide (LPS) from Gram-negative bacteria and monophosphoryl lipid A (MPL) from Salmonella. More recently, bacterial DNA was found to have strong immunostimulatory activity owing to the presence of unmethylated CpG dinucleotides $^{31,32}$. These and other bacterial products are bound by many different receptors that are expressed by DCs, macrophages and perhaps NK cells and other cells of the innate system. This induces their maturation, activation and production of pro-inflammatory cytokines. Many of these receptors belong to the family of Toll-like receptors that are located either on the surface of, or inside, cells that recognize invading pathogens ${ }^{33}$. Bacterial products are particularly good at activating cytotoxic T lymphocytes (CTLs), and because of that, they have been of interest to tumour immunologists ${ }^{34}$.

Recognition that different antigen-processing pathways control the presentation of antigenic peptides by either MHC class I molecules to $\mathrm{CD}^{+} \mathrm{T}$ cells (endogenous pathway) or $\mathrm{MHC}$ class II molecules to $\mathrm{CD}^{+}$ T cells (exogenous pathway) led to the development of a class of adjuvants that could deliver antigens to a desired processing pathway. Vaccines that are composed of all types of antigen, other than nucleic acids, use mainly the exogenous pathway for the delivery of antigen to APCs. This, in turn, favours the stimulation of $\mathrm{CD}^{+} \mathrm{T}$ cells and the production of antibody. Antigen is required to end up in the cytoplasm for processing by the proteasome and delivery to the endoplasmic reticulum (ER) for binding to $\mathrm{MHC}$ class I molecules ${ }^{35}$. Two classes of adjuvants effectively deliver antigens to the cytoplasm: microparticles, such as poly (D, L-lactic-co-glycolic acid) (PLGA) microspheres ${ }^{36}$ and virus-like particles ${ }^{37}$, as well as immunostimulatory complexes (ISCOMs) - a mixture of Quil A and cholesterol that forms micelles ${ }^{38}$. The particulate nature of the vaccine formulations that are imposed by these adjuvants promotes efficient delivery of antigen to APCs for presentation by both MHC class I and class II molecules. Heat-shock proteins might also belong to this category of adjuvants. They efficiently deliver antigen to the MHC class I pathway and in the process activate $\mathrm{APCs}^{39}$.

Generating the right type of immune response. Metastatic cancer is a systemic disease that is expected to be monitored by systemic immunity. Many primary tumours, however, originate at mucosal sites in which they are first encountered by the mucosal immune system. Increasing attention is being paid to antigens, adjuvants and routes of administration of vaccines that can effectively stimulate mucosal, as well as systemic immunity ${ }^{40}$. To understand immune responses against tumours at mucosal sites, a better understanding of the immune effector mechanisms that are responsible for protecting the mucosa are required. The mucosal immune system has evolved to keep the balance between a swift reaction against pathogens and no response to food or other environmental antigens and non-pathogenic bacterial flora. Mucosal vaccines need to maintain this well-regulated balance at the same time as strengthening the protective response. Our understanding of the specific characteristics and behaviour of cells of the immune system at mucosal surfaces is still not complete, but information is beginning to emerge with regard to the migration of lymphocytes and APCs to those sites and the induction of immunity versus tolerance ${ }^{41-44}$.

None of the cancer vaccines tested so far have been specifically designed to elicit mucosal immunity. One explanation for this obvious omission is that the aim of therapeutic vaccines is to eliminate residual disease, which might be considered as a role for systemic immunity. However, questions are beginning to arise about the potential of a particular immune response to be equally effective against tumours in different sites such as the lung, pancreas, liver or bone marrow. Most experiments carried out with animal models available at present, and especially with transplantable tumours that grow in subcutaneous sites, do not shed light on this subject. Another reason to consider whether a particular vaccine should be applied towards stimulating mucosal rather than systemic immunity is that therapeutic cancer vaccines are expected to boost an already existing, albeit weak, immune response rather than prime new responses. If the existing response was primed against a tumour that originated at a mucosal site - for example, colon cancer, cervical cancer, squamous cell carcinoma of the head and neck (SCCHN), lung adenocarcinoma and bladder cancer - this response might be more effectively boosted by a mucosal rather than systemic route of immunization. Understanding the role of mucosal immunity in cancer is going to be more important in the future for designing preventive cancer vaccines. If, for example, a vaccine is to be used for the prevention of polyps as a means of preventing colon cancer, this vaccine will have to stimulate the type of immunity that can recognize and react against tumour antigens when they are first expressed by the colon epithelium.

While mucosal immunity has not been given appropriate attention by tumour immunologists, the role of T HELPER 1 $\left(\mathrm{T}_{\mathrm{H}} 1\right)$ - versus $\mathrm{T}_{\mathrm{H}} 2$-type responses in antitumour immunity and the ability of cancer vaccines to elicit one or the other has been the focus of many studies. Ever since these two types of $\mathrm{CD} 4^{+} \mathrm{T}$ cell were described $^{45}$, their role in many different diseases has been well studied. With few exceptions, most effective antitumour immune responses in animal models have depended on the efficient generation of $\mathrm{T}_{\mathrm{H}} 1$-cell immunity that promotes CTL responses. The importance of $\mathrm{T}_{\mathrm{H}} 1$-cell immunity for tumour regression is also strengthened by the observation that progressive disease is characterized by an antitumour T-cell response that is skewed to $\mathrm{T}_{\mathrm{H}} 2$ cells $^{46}$. 
Even though in present animal models intentional skewing of the immune response to the $\mathrm{T}_{\mathrm{H}} 1$ type leads to tumour rejection, whereas a response skewed to the $\mathrm{T}_{\mathrm{H}} 2$ type seems ineffective, in the long run it might be a mistake to focus cancer-vaccine design on the generation of $\mathrm{T}_{\mathrm{H}} 1$-cell immunity. $\mathrm{T}_{\mathrm{H}} 2$-mediated immunity is characterized mainly by the production of antibodies that have been ineffective against tumour challenge in most animal models. However, in patients, passively administered antibodies that are specific for antigens expressed by tumour cells have shown antitumour effects in B-cell lymphomas ${ }^{47}$, breast cancer ${ }^{48}$ and colon cancer $^{49}$. Designing vaccines that promote $\mathrm{T}_{\mathrm{H}} 2$-type responses to generate such antibodies in vivo would seem to have numerous advantages over the passive administration of antibody. This is already being done, with some success, using vaccines against IDIOTYPES expressed by B-cell lymphomas ${ }^{50}$. Vaccine-elicited antibodies can mediate direct effects against tumour cells by fixing complement or facilitating ANTIBODY-DEPENDENT CELLULAR CYTOTOXICITY (ADCC). A more important function of tumour-specific antibodies is opsonization of tumour cells to promote their uptake by APCs. Several cancer-vaccine trials have aimed to elicit tumour-specific antibodies and have succeeded. However, owing to advanced stages of disease, the antitumour effects of such antibodies have not been significant ${ }^{51}$.

Designing a vaccine that will skew a response to one type (for example, $\mathrm{T}_{\mathrm{H}} 1$ ) or one effector mechanism (for example, CTL) might be an acceptable strategy for present therapeutic vaccinations in which immediate effects are sought. This strategy is unlikely to be beneficial for cancer prevention or in treating early disease in which many mechanisms are required to synergize to create as large a pool as possible of effector cells to guarantee a large pool of memory cells. Until recently, most cancer vaccines were based almost exclusively on MHC class I-restricted peptides ${ }^{52}$. These vaccines did generate some CTL activity, but the frequency and duration of these responses was uniformly low. The requirement for simultaneous activation by a cancer vaccine of many components of the immune system cannot be overestimated.

Elicitation of long-term memory. Immune memory is an important protective mechanism that some vaccines can elicit and others cannot. The nature of immune memory and the requirements for its generation and maintenance have only recently begun to be elucidated $^{53,54}$. The main problem that has hampered this field of investigation has been the relative paucity of specific markers that could separate memory $T$ cells from other T cells. Chemokine receptors have recently been used successfully to distinguish between functional subsets of $\mathrm{T}$ cells including memory cells ${ }^{55}$. These, and additional markers, such as mucin-like glycoproteins ${ }^{56}$, are starting to be reported. They will help in the evaluation of the role of tumour antigens, adjuvants and routes of injection not only with regard to the complexity and intensity of the immune response they elicit, but also for the type of memory response that is generated.
There is a consensus that a strong primary immune response is required to give rise to a large pool of memory cells. What affects the longevity of memory $\mathrm{T}$ cells, however, is not fully understood and there is much controversy with regard to the role of antigen in this process $s^{54,57}$. For therapeutic cancer vaccines, these questions are of great importance. The immune system of a cancer patient is exposed to the tumour antigens over a relatively long period of time and the vaccine based on some of these antigens is expected to boost immunity in their presence. It is not known whether the tumour-specific $\mathrm{T}$ cells that are present in the patient before vaccination are effector cells or a mixture of effector cells and memory cells. Several papers have claimed the existence of tumour-specific memory cells ${ }^{58-60}$. However, because of the inability to separate clearly effector cells from memory cells and the chronic presence of tumour antigen, it is not clear to what subset of T cells tumour-specific cells in cancer patients belong and how they are affected by vaccination. It is also not clear whether long-term memory can ever be achieved in chronic diseases such as cancer. Certain requirements, especially the need for activation of $\mathrm{T}_{\mathrm{H}}$ cells and innate immunity, are coming to light in the setting of chronic viral diseases ${ }^{61}$ and to a more limited extent in cancer ${ }^{62,63}$. As reported recently, during the generation of T-cell memory there is a progression from naive cells that become effector cells when antigen is introduced, to effector memory cells when antigen becomes limited, to central memory cells after the clearance of antigen ${ }^{64}$. Although prophylactic cancer vaccines in healthy young adults would be expected to activate this entire differentiation pathway, it is less clear how a therapeutic vaccine might do that in the presence of chronic antigen and many existing cell populations specific for that antigen.

\section{Additional challenges facing cancer vaccines}

Aging immune system. Patients with cancer in whom cancer vaccines are presently being tested are, almost without exception, of advanced age ( $65-80$ years), many decades after the thymus has stopped producing naive $\mathrm{T}$ cells. Therefore, the generation of an effector-cell population in response to a vaccine depends on the recognition of the vaccine antigen by one or more memory cells in the T-cell repertoire of the patient. Among the T cells that respond to the vaccine there might or might not be the 'best fit' ones that would have been selected from a large pool of naive clones earlier in life. In mouse models, it can be clearly shown that young mice make stronger primary responses than old mice. Generation of the primary response and the conversion to memory is compromised with age $e^{65,66}$. This is due to ageassociated changes in the function of many components of the immune system ${ }^{67-69}$. At present, there is an important discrepancy between preclinical studies in mouse models and clinical trials of cancer vaccines. Few studies, if any, use old mice. Those that do, report an age-related increase in susceptibility to cancer due to changing patterns of T-cell subsets ${ }^{70}$, as well as difficulty in the induction of effective antitumour immune responses ${ }^{71}$. 
a

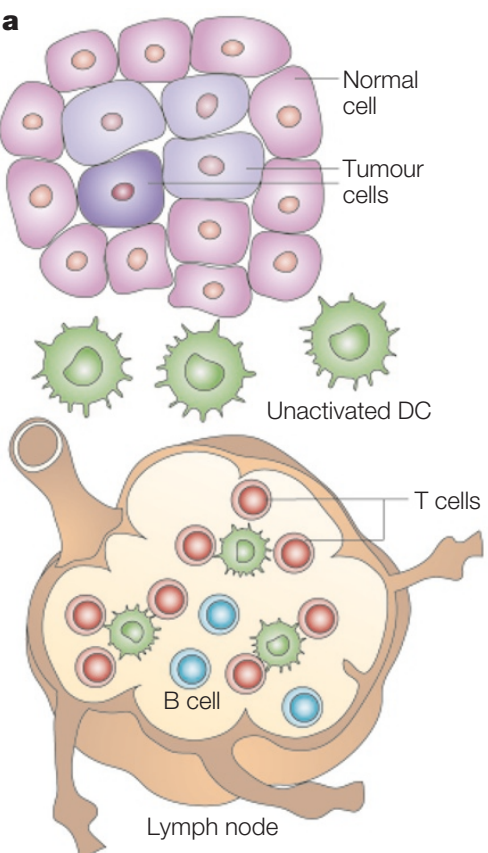

c
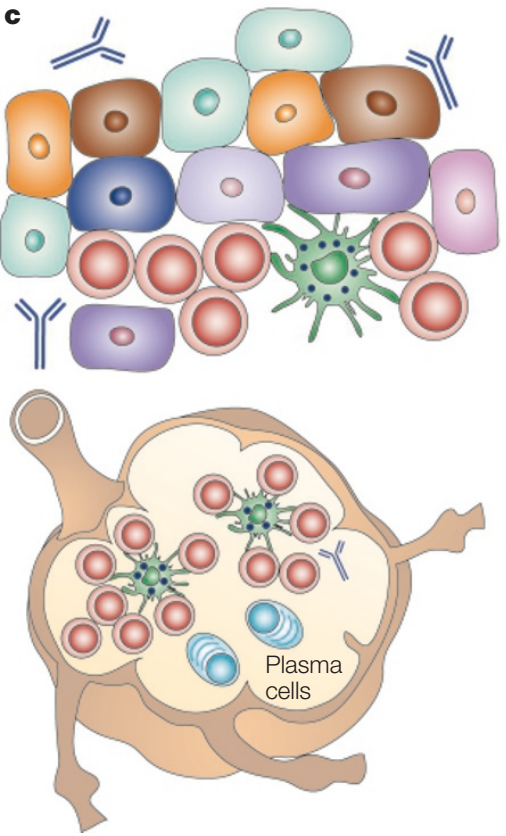

b

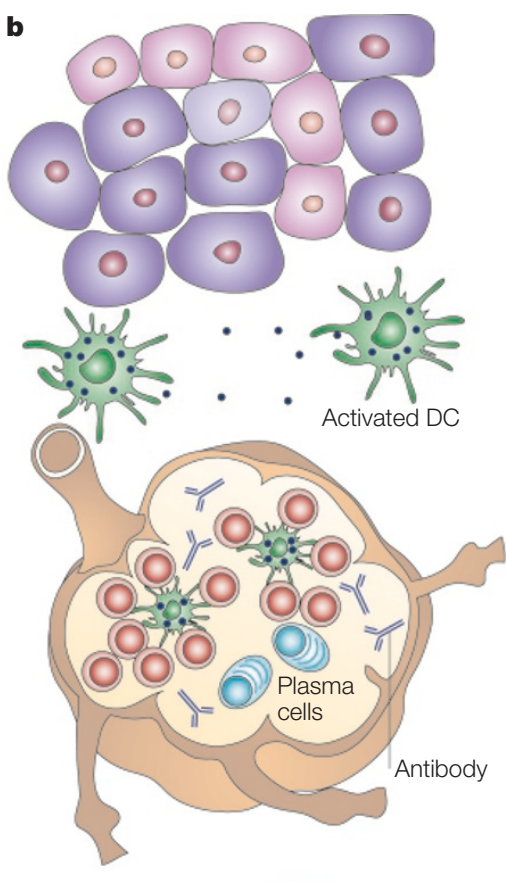

d

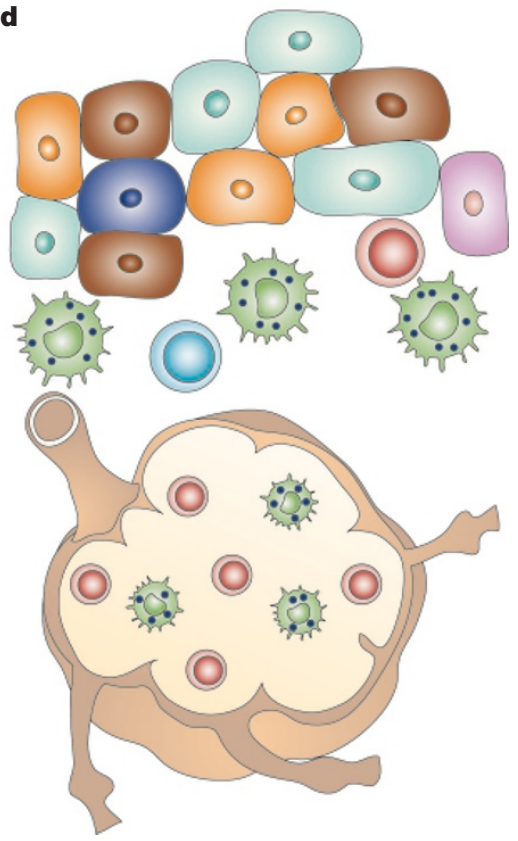

Figure 1 | A probable model of the evolution and fate of antitumour immune responses that develop coincidently with tumour growth. a | Tumours develop over a long period of time through a process of accumulation of many mutations. While the tumour is small and does not present a significant danger to the integrity of the organ of origin, the immune system remains ignorant of its presence. Dendritic cells (DCs) in the surrounding tissue are not activated and as a result $T$ and $B$ cells in the lymph node remain in a resting state. $\mathbf{b} \mid$ When the tumour becomes larger, heterogeneous and ultimately malignant, damage to the normal tissue and products made by the tumour cells alert the immune system mainly through the activation of resident DCs. Activated DCs that have taken up products derived from damaged normal tissues and tumours, traffic to the draining lymph node in which they begin to present these products as antigens to naive $T$ and B cells. The extent of DC activation determines the extent of lymphocyte stimulation. This in turn is regulated by many factors that determine the immune competence of the patient, including age. c | Tumour-specific T cells, antibodies and activated DCs reach the tumour site and attempt to destroy the tumour. They are only partially successful owing to an already large tumour size and marked tumour heterogeneity that allows the tumour to evade many immune effector mechanisms. d | The tumour that has evaded the initial immune response continues to grow, disseminate and actively suppress local, as well as systemic, immunity illustrated by the presence at the tumour site of DCs, T and B cells that are not activated and do not exert their respective functions.

In recognition of the fact that therapeutic vaccines for cancer will be given mostly to older individuals, increasing attention should be given to designing vaccines that can overcome at least some age-related problems. For example, engagement of the co-stimulatory molecule 4-1BB (CD137) was shown to amplify T-cell responses in aged mice ${ }^{72}$ and, although not yet tested, engagement of other co-stimulatory molecules or inactivation of negative regulators, such as cytotoxic $\mathrm{T}$ lymphocyte antigen 4 $(\text { CTLA } 4)^{73}$, might have similar effects. Furthermore, although many adjuvants might work well in young mice, only some might enhance immune responses in aged individuals. CpG-DNA seems to be especially good at enhancing cellular and humoral immunity and promoting $\mathrm{T}_{\mathrm{H}} 1$-type responses in old mice ${ }^{74}$.

Age-associated immune deficiency indicates that paediatric cancer patients might be better candidates than adult patients for therapeutic cancer vaccines. Few such trials have been carried out. Results from one DCbased vaccine trial conducted on children aged between 3 and 17 years with relapsed neuroblastomas, sarcomas and renal cancers, are unfortunately only slightly more encouraging than results from clinical trials in aged patients $^{75}$. This shows that even in a young patient, there is an influence of previous therapy and/or the advanced stage of the tumour on the immune system, and indicates that successful vaccination strategies would require vaccination not only at an early age, but also in early disease and in the absence of immunosuppressive standard therapy.

Tumour-induced immunosuppression and immune evasion: By the time a tumour is diagnosed, there have been many interactions between the tumour and the immune system (FIG. 1). A tumour might have been growing slowly without much destruction of the surrounding normal tissue and so might not have been detected by the immune system. During that time, tumour cells acquire additional mutations, some of which facilitate growth and invasion. As the tumour becomes larger and begins to cause tissue destruction, in addition to defense processes, such as wound repair and clotting mechanisms, the adaptive immune system is also alerted owing to the activation of DCs. These cells pick up tumour and tissue debris and 'ferry' it to the draining lymph nodes for presentation to $\mathrm{T}$ cells. The presence of tumour-specific cellular and humoral responses in cancer patients indicates that the immune system has 'seen' the tumour. The loss of expression of various tumour antigens or MHC molecules by tumour cells indicates that the immune system has tried to get rid of the tumour. Progressive tumour growth, however, indicates that the tumour has ultimately evaded immune defenses. This process of immunosurveillance, which changes the tumour but does not result in complete tumour rejection, is known as 'cancer immunoediting' ${ }^{\text {'76. }}$.

Many ways in which tumours influence the immune system have been described and functional defects have been documented in many immune effector mechanisms. The maturation and function of 
DCs is inhibited in cancer patients ${ }^{77,78}$. Marked defects are also seen in T-cell activation and function, which was first reported in mice with tumours ${ }^{79}$ and later found in patients with many types of tumour ${ }^{80}$. These effects can be mediated by IL-10, transforming growth factor- $\beta$ (TGF- $\beta$ ) and other cytokines that tumours produce ${ }^{81-83}$, or by other less well defined soluble factors $^{84}$ or cell-surface molecules ${ }^{85}$ expressed by tumour cells.

Suppression of adaptive antitumour immunity can also be mediated by 'improper activation' of innate immunity. It has been reported that the activation of macrophages and polymorphonuclear cells in response to the tumour induces a state of oxidative stress in cancer patients that markedly suppresses the function of $\mathrm{T}$ cells ${ }^{86}$. Activation of NKT cells that might result in the production of high levels of IL-13 has also been reported to suppress tumour immunity ${ }^{87}$. There is an ongoing effort to understand these immunosuppressive mechanisms at the molecular level to allow therapeutic intervention. There are encouraging reports that at least some of these defects have been reversible through vaccination in a small number of patients ${ }^{88,89}$. These studies will now have to extend to understanding the role in tumour immunity of the recently described regulatory $\mathrm{T}$ cell $\mathrm{s}^{90}$. A subpopulation of $\mathrm{CD} 4{ }^{+} \mathrm{CD} 25^{+} \mathrm{T}$ cells has been shown to suppress autoimmunity ${ }^{91}$ and therefore might be specifically expanded in response to the increased presentation of autoantigens during tumour growth. The limited number of studies that have been carried out with tumours in mice indicate a potential benefit from depleting these cells ${ }^{92}$.

A complete understanding of the immune system of patients with tumours is important, especially when trying to manipulate it with therapeutic cancer vaccines. Many of the immunosuppressive mechanisms are common to different tumour types and devising a treatment regiment to reverse immunosuppression before therapeutic vaccination might produce better results.

\section{Therapeutic cancer vaccines}

Because many primary tumours can be surgically removed and there is often a long period of time before the tumour recurs at metastatic sites, cancer vaccines have been proposed as therapy that are designed to elicit and/or boost antitumour immunity in patients with minimal residual disease, thereby preventing or prolonging the time to recurrence. Few vaccines have been tested in that optimal clinical setting. Most phase I and II studies have been carried out, so far, in late stage disease and in the presence of a relatively large tumour burden after the failure of standard therapies. Even under the best of circumstances, the success of therapeutic vaccines will depend on the ability of the immune system to overcome tumour-induced, therapy-induced or age-induced immunosuppression. An additional factor that influences the effectiveness of therapeutic vaccines will be the outgrowth of tumour cells that, for one reason or another, can evade the immune response (FIG. 2).
The therapeutic vaccine effort that has accumulated the most clinical results has been the development of vaccines for melanoma patients. It started with the use of cell lysates from allogeneic tumourcell lines in combination with adjuvants ${ }^{93,94}$ or protein products that are shed into the supernatants of such cell lines ${ }^{95,96}$. Hundreds of patients with advanced stage III or IV melanoma, many with metastatic disease having failed chemotherapy, have participated in these studies. In the case of one of these vaccines, Melacine (Corixa Corporation, Seattle, Washington, USA), phase I and II trials in stage IV patients showed a $10-20 \%$ response rate (clearing of some metastatic sites) and in another $10-20 \%$ of patients disease was stabilized (no progression for various periods of time of tumours that were growing at the start of the vaccine protocol). In a multi-centre phase III study, Melacine was compared with a four-drug chemotherapy regimen and the response rates and survival were the same ${ }^{97}$. The advantage of Melacine over chemotherapy was that it was non-toxic and therefore allowed a better quality of life compared with chemotherapy. For that reason, Melacine is now available on prescription to patients in Canada and is awaiting approval in the United States. A similar vaccine preparation, Canvaxin, was evaluated in $\sim 1,000$ stage IV melanoma patients and compared with an equal number of patients who were treated with surgery and chemotherapy during the same time period, but did not receive the vaccine. This single-institution study showed a small, but statistically significant, increase in the overall survival in the vaccinated group ${ }^{94}$. The vaccine is now being tested in a multi-centre phase III randomized trial.

More recent versions of cancer vaccines that are based on autologous tumours and their various products include modified tumour cells ${ }^{98,99}$ and tumourderived heat-shock proteins ${ }^{100}$. The latest report from a phase I trial in 35 patients with non-small-cell lung cancer vaccinated with irradiated autologous tumour cells that are engineered to secrete GM-CSF, shows post-vaccine infiltration of metastatic sites with macrophages, granulocytes and lymphocytes, as well as DELAYED-TYPE HYPERSENSITIVITY (DTH) responses against unmodified tumour cells in most patients. Correlation of these events with the clinical outcome is less clear, with only five patients showing stabilization of disease $\mathrm{e}^{101}$. Similarly, the latest report on the autologous tumour-derived heat-shock protein gp96 vaccine in 39 patients with resected stage IV melanoma indicates that 11 patients had increases in melanoma-specific T-cell reactivity, of which two patients had a complete response (disappearance of all detectable tumours) and three patients had stable disease ${ }^{100}$.

DC-based vaccines ${ }^{102}$ are the newest development in cancer vaccine design. DCs can be loaded with autologous or allogeneic tumours ${ }^{103}$, apoptotic bodies ${ }^{104}$, tumour lysates ${ }^{105}$, tumour RNA ${ }^{106,107}$ and tumour DNA ${ }^{108,109}$. Most of these preparations have shown to be immunogenic and have the potential for 
a

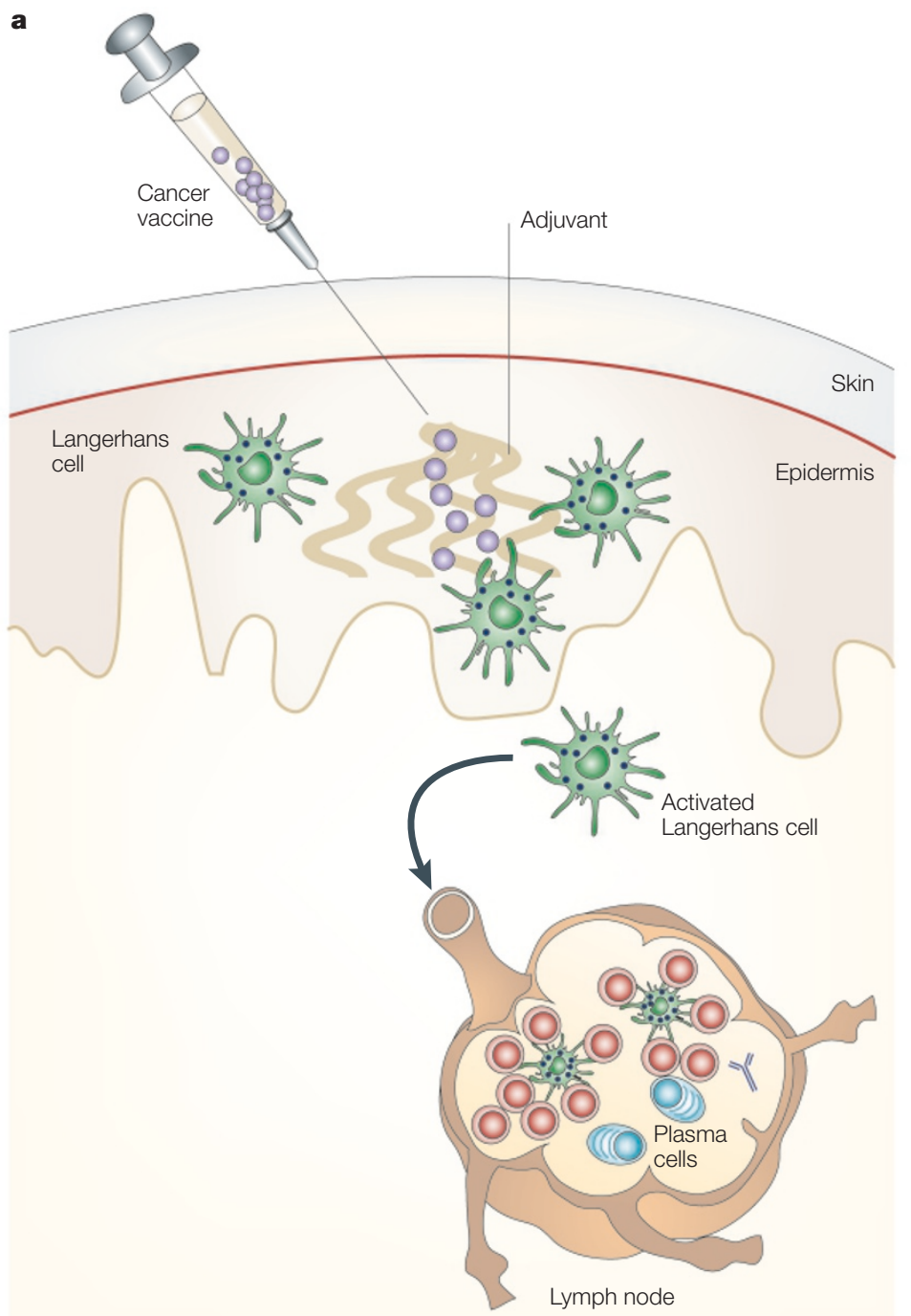

b

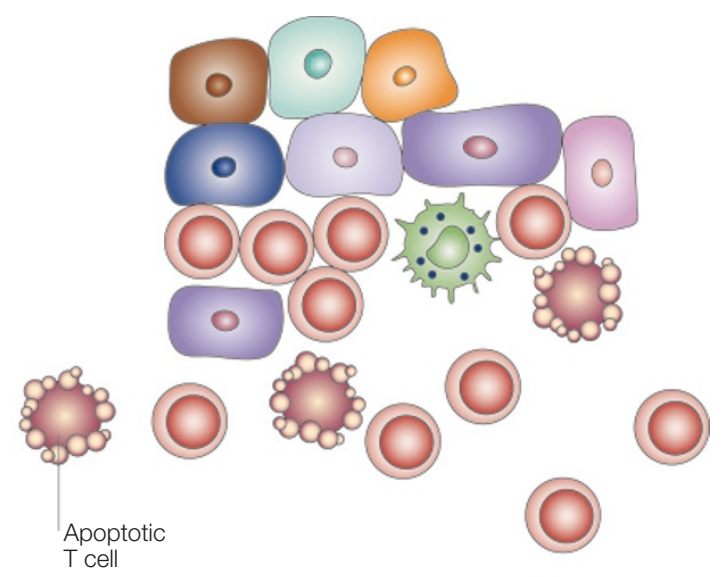

c

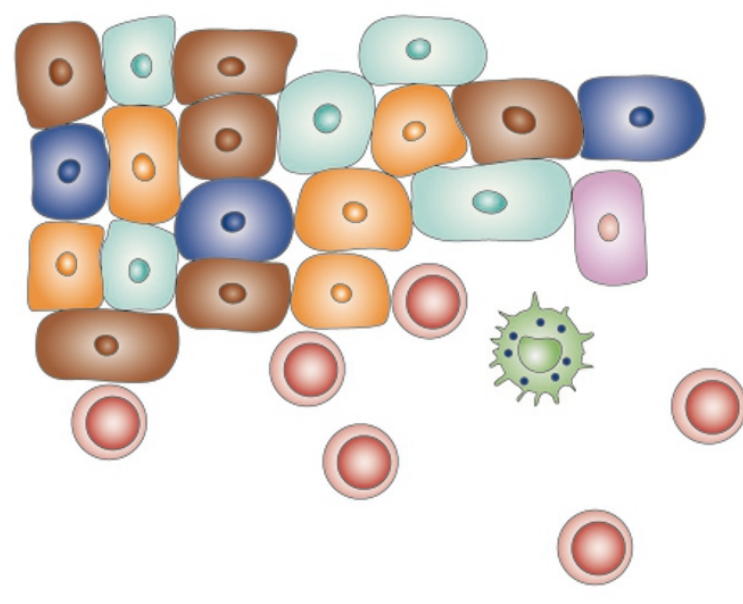

Figure 2 | Manipulation of antitumour immune responses by therapeutic vaccination. a | Therapeutic vaccines are administered after the tumour is diagnosed, at the time of interactions between the tumour and the immune system that correspond to parts $\mathbf{c}$ and $\mathbf{d}$ in FIG. 1. In the most optimal clinical setting, therapeutic vaccines intend to boost immunity against minimal residual disease and prevent the outgrowth of metastases shown in parts $\mathbf{b}$ and $\mathbf{c}$. A vaccine based on autologous tumour or defined tumour antigens is administered in an immunostimulatory preparation (with adjuvant) that can activate Langerhans cells - dendritic cells (DCs) that reside in the epidermis. Activated Langerhans cells take up the tumour antigens and traffic to the draining lymph node in which they present antigens to T cells. B cells are also activated and the expected outcome is clonal expansion of tumour-specific T cells and the production of tumour-specific antibodies. b | Tumour-specific T cells migrate to the sites of tumour metastases where they attempt to kill tumour cells that express antigens contained in the vaccine. Their function is compromised by the immunosuppressive tumour microenvironement, which affects their function and leads to their death. Furthermore, tumour heterogeneity has been established over time. Some tumour cells have lost expression of antigens that are targeted by the immune response and others have become resistant to immune effector mechanisms. This allows many of the cells to evade the immune attack. $\mathbf{c} \mid$ Metastases that continue to grow are composed of tumour cells that lack antigens recognized by $T$ cells and antibodies or are otherwise resistant to immune destruction.

tumour rejection in animal models, and are undergoing evaluation in the clinic at present. Results from a phase I study of a vaccine composed of DCs that were loaded with messenger RNA encoding prostate-specific antigen (PSA) have been reported recently. Vaccination of prostate cancer patients that had raised levels of expression of PSA induced T-cell responses against PSA in most patients and the log slope of PSA was temporarily decreased ${ }^{110}$, indicating perhaps that growth of the tumour was slowing down.
Shared tumour antigens can be produced as synthetic or recombinant proteins and are, therefore, ideally suited for prophylactic vaccination of individuals who do not have a tumour, but are at high risk of developing a tumour. Yet, these antigens have, so far, been tested exclusively in therapy of advanced disease $\mathrm{e}^{17,111-121}$. As with whole tumour-based vaccines, tumour antigenbased vaccines have shown impressive results in preventing tumours in animal models and only marginal results in therapy of advanced disease in both animals and patients ${ }^{122}$. 


\section{Prophylactic cancer vaccines}

Many of the potentially insurmountable problems that diminish the therapeutic effects of cancer vaccines, would not need to be considered in the setting of cancer prevention. An immune system that is primed to anticipate tumour antigens, would be expected to destroy the tumour before it becomes clinically obvious, heterogeneous, and can suppress and evade the immune response (FIG. 3). In 2002, Merck\&Company Inc. announced preliminary results of a study testing the company's vaccine against human papillomavirus type 16 (HPV16) ${ }^{123}$. Infection with HPV is a known cause of most cervical cancers and HPV16 is found in over $50 \%$ of these tumours. HPV is a common infection in the general population and the immune response to the virus protects against chronic infection that can lead to cancer ${ }^{124}$. In a minority of individuals, the immune response seems not to be strong enough or of the right type, allowing the establishment of chronic infection. The results showed, after the first 2 years of a 4-year study on 2,392 women aged between 16 and 23 years who were randomly assigned to the vaccine or a placebo, that in the placebo group, $3.8 \%$ of women were infected with HPV16 annually compared with no infections in the vaccinated group. These are spectacular results considering that 150,000 women in developing countries die annually of cervical cancer that might now be reduced by preventing the initial infection with virus. If a world-wide HPV vaccination programme were to start in 2010, it is estimated that there would be no cases of cervical cancer by 2050 (REF. 125). Results from vaccines against hepatitis $B$ virus (HBV), which is also known to cause cancer in chronically infected individuals, already supports the expectation of lowered cancer rates. In Taiwan, where a national vaccination programme against HBV was started in 1986, there has been a marked reduction in the incidence of childhood liver cancer ${ }^{126}$. In the HBV vaccination programme in The Gambia, vaccination of
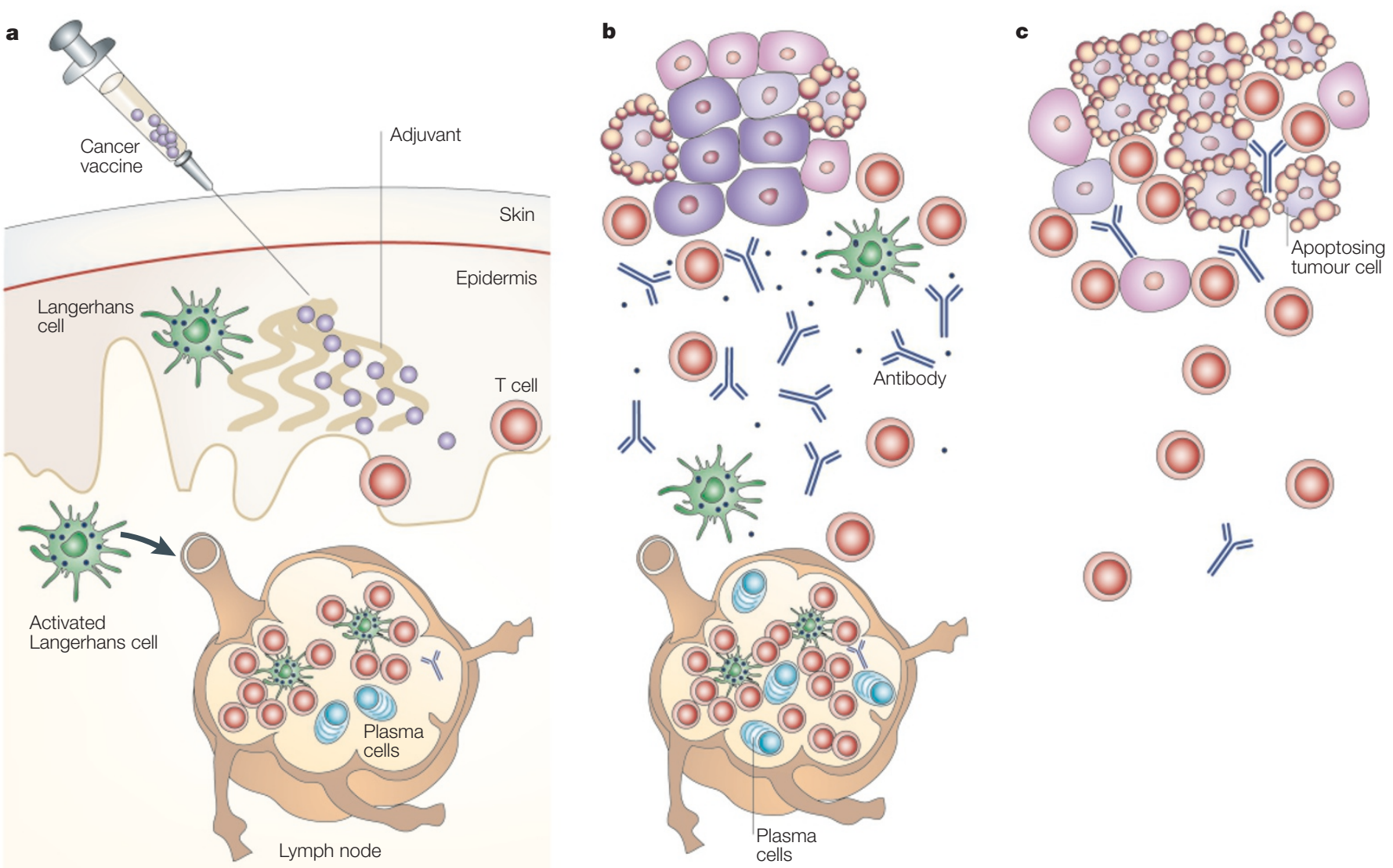

Figure 3 | Manipulation of antitumour immune responses by prophylactic vaccination. a | Prophylactic vaccines would be administered before the occurrence of tumours to individuals who are at high risk for developing tumours or have been diagnosed with premalignant changes in target tissues. A vaccine based on antigen/s that are expected to be expressed by the anticipated tumour is administered in an immunostimulatory preparation (with adjuvant) that can activate Langerhans cells - dendritic cells (DCs) that reside in the epidermis. Activated Langerhans cells take up the tumour antigens and traffic to the draining lymph node in which they present antigens to T cells. B cells are also activated and the expected outcome is clonal expansion of tumour-specific T cells and the production of tumour-specific antibodies. This clonal expansion of effector cells is followed in time by the generation of a pool of memory cells that are specific for the tumour antigen/s. b | If a tumour begins to grow sometime in the future, tumour antigens that reach the draining lymph node will reactivate tumour-specific memory cells and elicit a swift secondary immune response. This response will be characterized by large numbers of effector T cells, high titre of antibodies and continuous activation of DCs at the tumour site, for continuous processing and presentation of tumour antigens and further amplification of the immune response. $\mathbf{c | T h e ~ i n c i p i e n t ~ t u m o u r ~ h a s ~ n o t ~ b e e n ~ a l l o w e d ~ t o ~ g r o w ~ l a r g e ~ a n d ~ h e t e r o g e n e o u s ~ a n d ~ i s ~ e a s i l y ~ e l i m i n a t e d ~ b y ~ t h e ~ p r e p a r e d ~}$ immune response. Moreover, the memory compartment is further expanded by this tumour-mediated boost. 


\section{Box 1 | Prophylactic vaccines for breast cancer}

Many young women with hereditary risk of breast and ovarian cancer, especially those with mutations in the gene encoding breast cancer 1, early onset (BRCA1) or BRCA2 (REF. 152), are, at present, offered prophylactic mastectomy and/or oophorectomy. Several large studies show that these procedures decrease the risk of both cancers ${ }^{152-156}$. Other presently available options are chemoprevention or frequent surveillance. All of these options are associated with considerable risks ${ }^{157}$. Breast cancer vaccines have not been one of the prophylactic options, in spite of the fact that promising breast-cancer antigens have been defined and, to the extent possible, shown to be safe in phase I and II clinical trials in patients with breast cancer ${ }^{17,111,115,119,158}$. The two main arguments put forward against the vaccines are: first, safety (potential cross-reactivity of the elicited immune response with normal tissues); and second, the need for a large number of patients and long-term observation to establish efficacy. In my view, neither of these arguments is valid. In the most extreme case of cross-reactivity, autoimmune destruction of normal breast or ovarian tissue should have no more serious consequences than their surgical removal. Similarly, if the statistical approaches that are used now to select an appropriate number of individuals at high risk allow evaluation of efficacy of prophylactic surgery or chemotherapy, the same statistics, the same number of patients and the same follow-up time can be applied to the evaluation of vaccine efficacy.

newborns has had $83 \%$ efficacy against acute infection and $95 \%$ efficacy against chronic infection ${ }^{127}$. The effect on liver cancer is still unknown, because the vaccinated individuals have not reached the advanced age at which the cancers arise. Knowing the strength of the association between chronic HBV infection and liver cancer, it is highly probable that the results will match the expectation of a markedly reduced incidence of cancer.

There are numerous cancers without a known virus cause that have a bigger impact in terms of human suffering, which could also be prevented with vaccines ${ }^{122,128,129}$. Viral antigens are no different from tumour antigens in that they both fail to elicit good immune responses in a therapeutic setting. An HPV16 peptide-based vaccine in women with advanced cervical carcinoma elicited only minor responses in the face of progressive disease ${ }^{114}$. A similar vaccine in women with an earlier stage of disease — a high-grade HPV16-positive cervical intraepithelial neoplasia - elicited slightly more convincing immune responses that did not translate into eradication of the

\section{Box 2 | Prophylactic vaccines for pancreatic cancer}

Patients with hereditary pancreatitis caused by the common mutations in the gene encoding trypsin have a median age of onset of the disease around 10 years of age. Half of these patients develop chronic pancreatitis and are at increased risk of pancreatic cancer ${ }^{159}$. At present, screening is recommended to patients with hereditary pancreatitis of aged 40 years and over, and if cancer is suspected, removal of the entire pancreas is the prophylactic option. This is a drastic measure with significant and lasting co-morbidities, such as brittle diabetes mellitus.

Screening detects early mutations in premalignant lesions that are known to be precursors of pancreatic cancer, defined as pancreatic intraepithelial neoplasia $(\text { PanIN })^{148}$. The number of mutations that accumulate over time characterizes the stage of progression of these lesions towards malignancy. Pancreatic cancer vaccines have so far been tested only in patients with late-stage pancreatic cancer ${ }^{4,111}$. These same vaccines could be a reasonable prophylactic option for patients with chronic pancreatitis, who after screening show cancer-promoting mutations and advanced PanINs. Although a reduction of cancer incidence would be the ultimate end point, that might take a long time to reach, vaccinated patients could be screened as early as a year after vaccination for the disappearance of mutations as a way of evaluating the vaccine efficacy. virus ${ }^{130}$. Results from these trials are exactly the same as results that are obtained in many similar trials with other tumour antigens. The antigen, the formulation and the delivery of vaccine are all important for its efficacy, but the appropriate timing of administration might be the most important predictor of success for cancer vaccines.

The antigen has an important role, however, in assuring the safety of the vaccine-elicited immune response. Viral antigens that function as tumour antigens are expected to elicit a response that is specific only for the tumour cells that harbour them. However, many of the well-defined tumour antigens are also expressed by normal tissues, albeit in a reduced or modified form, and these tissues could potentially be damaged. This potential has to be considered most seriously in the setting of cancer prevention. Many pre-clinical studies of vaccines based on tumour antigens have put a special emphasis on defining tumour-specific epitopes and vaccine formulations that will prevent tumour growth, but not damage normal tissues. Results with several antigens indicate that they could be safely administered to individuals at risk for developing cancer. For example, mucin 1 glycoprotein is expressed by normal epithelial cells and by adenocarcinomas of the breast, pancreas, colon, lung, ovary, prostate and several others. It is also expressed by many myelomas and some B-cell lymphomas. Learning how to target the immune response against mucin 1 to tumours expressing mucin 1 could potentially be used for the prevention of all these tumours. Many groups are exploring this potential by defining various epitopes on mucin 1 that can be used to elicit tumour-specific immune responses ${ }^{131-137}$. There are quantitative and qualitative differences in the expression of mucin 1 between normal and malignant cells. Tumours overexpress mucin 1 and they also markedly underglycosylate this otherwise heavily O-glycosylated molecule. The immune system recognizes both differences and, as seen in animal models from transgenic mice to chimpanzees, it can destroy mucin-1-expressing tumours at the same time as ignoring normal tissues that express mucin 1 (REFS 12,138-142). Similar examples can be provided by reviewing the work on other well-known antigens, such as CEA ${ }^{26,143-145}$ and HER2 (REFS 11,17,119,146). In addition to these antigens, which can be used safely without risk of autoimmunity, antigens, such as the melanoma antigens and PSA, are known to induce autoimmunity that can be tolerated, such as vitiligo or autoimmune prostatitis.

\section{The future of cancer vaccines}

Having done as much as is possible to show the efficacy and safety of several well-known tumour antigens, it is important to decide what will be the next step in developing these as effective cancer vaccines. One option is to continue testing vaccines in cancer patients in small phase I and II trials, with individual antigens in different forms, in different vaccine formulations and with different adjuvants, taking advantage of new technological developments and hoping for improvements in efficacy. The best example of a cancer vaccine that has followed this option is the anti-idiotype vaccine for B-cell lymphomas ${ }^{147}$ - a prototype of a therapeutic cancer 


\section{Box 3 | Prophylactic vaccines for colorectal cancer}

Of the 130,000 cases of colorectal cancer that are diagnosed in the United States each year, 15\% are hereditary with 5\% due to either familial adenomatous polyposis syndrome (FAP) or hereditary non-polyposis colorectal cancer syndrome (HNPCC). Mutations that are associated with these two syndromes are known, and individuals who have one or more of these mutations are at increased risk of colorectal cancer ${ }^{162}$. Large-scale clinical trials, such as those that use non-steroidal anti-inflammatory drugs (NSAIDs) have been carried out testing chemoprevention of polyps as a means of preventing colon cancer. If this prevention approach is to be effective, individuals at risk will need to take the drug for life. This brings up the issues of drug toxicity, drug resistance, as well as non-compliance. Alternatively, the same individuals could be immunized against a tumour antigen that is known to be differentially expressed by polyps versus normal tissue, and expressed by all colorectal adenocarcinomas. Dysregulated expression of mucin genes in polyps has been documented ${ }^{163}$. Colon-tumour antigen mucin 1 is not expressed by normal colon, but it is expressed by adenomatous polyps in the tumour-associated underglycosylated form ${ }^{164}$. The hope for a prophylactic vaccine containing mucin 1 would be that it would prevent the occurrence or recurrence of polyps. This is an end point that can be used to evaluate the efficacy of this vaccine in a relatively short period of time.

vaccine based on a unique tumour antigen. If the same approach is applied to shared tumour antigens, it will yield vaccines for the treatment of a limited number of patients at major medical centres in developed countries. However, the impact on cancer as a global health problem will be negligible.

The other option is to make a decision that cancer vaccines that have shown efficacy and safety in preclinical studies are relevant for the prevention of cancer and to begin to test them as such. Trials to test the ability of mucin 1, CEA or HER2 vaccines to prevent breast cancer in women at high risk should pose no bigger logistical and financial challenges than similar trials of other preventive modalities, among which random- ized trials on hundreds of women that are treated with double mastectomies or oophorectomies are taking place (BOX 1). When prevention becomes a stated goal of at least some cancer vaccines, a different approach will be encouraged for the identification of new tumour antigens. Instead of continuing to focus on the tumour as a source of antigens, the emphasis could shift to premalignant lesions. Many such lesions are known for pancreatic cancer $^{148}$ (BOX 2), prostate cancer ${ }^{149}$, colon cancer ${ }^{150}$ (BOX 3), esophageal cancer ${ }^{151}$ and others. Having vaccines that could prevent the progression of these lesions to cancer would make the cancer screening efforts much more useful than they are now and set the stage for a more general use of prophylactic cancer vaccines in the near future.
1. Jenner, E. in Sampson Low (Soho, London, 1798). Andre, F. E. Vaccinology: past achievements, present roadblocks and future promises. Vaccine 21, 593-595 (2003) Ward, S. et al. Immunotherapeutic potential of whole tumour cells. Cancer Immunol. Immunother. 51, 351-357 (2002).

. Jaffee, E. M. et al. Novel allogeneic granulocytemacrophage colony-stimulating factor-secreting tumo vaccine for pancreatic cancer: a phase I trial of safety and immune activation. J. Clin. Oncol. 19, 145-156 (2001).

5. Dranoff, G. GM-CSF-based cancer vaccines. Immunol. Rev 188, 147-154 (2002)

6. Ludewig, B. et al. M. Immunotherapy with dendritic cells directed against tumor antigens shared with normal host mune disease. J. Exp. Med. cells results in severe

191, 795-804 (2000). This paper shows data from transgenic mice that a dendritic cell (DC)-based vaccine with antigens th are expressed by tumours, as well as by various normal tissues, can cause fatal autoimmune diseases, such as autoimmune diabetes, arteritis and myocarditis.

7. Overwijk, W. W. et al. Vaccination with a recombinant vaccinia virus encoding a 'self' antigen induces autoimmune vitiligo and tumor cell destruction in mice: requirement for CD4+ T lymphocytes. Proc. Natl Acad. Sci. USA 96 2982-2987 (1999).

8. van Elsas, $A$, et al. Elucidating the autoimmune and antitumor effector mechanisms of a treatment based on cytotoxic T lymphocyte antigen- 4 blockade in combination with a B16 melanoma vaccine: comparison of prophylaxis and therapy. J. Exp. Med. 194, 481-489 (2001).

9. Dudley, M. E. et al. Cancer regression and autoimmunity in patients after clonal repopulation with antitumor lymphocytes. Science 298, 850-854 (2002). This paper convincingly illustrates the power of tumour-specific $T$ cells directed against self/differentiation antigens that are overexpressed by tumours. Adoptive transfer of these cells into by tumours. Adoptive transfer of these cells into metastatic melanoma patients resulted in the regression of melanoma, but also in the onset of
vitiligo - autoimmune melanocyte destruction.
10. Heimberger, A. B. et al. Dendritic cells pulsed with a tumorspecific peptide induce long-lasting immunity and are effective against murine intracerebral melanoma. Neurosurgery 50, 158-166 (2002).

11. Pupa, S. M. et al. Prevention of spontaneous neu-expressing mammary tumor development in mice transgenic for rat proto-neu by DNA vaccination. Gene Ther. 8, 75-79 (2001).

12. Soares, M. M., Mehta, V. \& Finn, O. J. Three different vaccines based on the 140-amino acid MUC1 peptide with seven tandemly repeated tumor-specific epitopes elicit distinct immune effector mechanisms in wild-type versus MUC1-transgenic mice with different potential for tumor rejection. J. Immunol. 166, 6555-6563 (2001). This paper shows the importance of not only the right antigen, but also the right adjuvant for an effective antitumour vaccine. Mucin 1 peptide was admitumour vaccine. Mucin 1 peptide was All induced immune responses, but only one (DCs All induced immune responses, but only one (DCs loaded with mucin 1) induced tumour reje
effective immune response did not cause effective immune response did not cause

autoimmunity in mucin 1-transgenic mice.
Van Der Bruggen, P. et al. Tumor-specific shared antigenic peptides recognized by human T cells. Immunol. Rev. 188, 51-64 (2002).

14. Henderson, R. A. \& Finn, O. J. Human tumor antigens are ready to fly. Adv. Immunol. 62, 217-256 (1996).

15. Scanlan, M. J., Gure, A. O., Jungbluth, A. A., Old, L. J. \& Chen, Y. T. Cancer/testis antigens: an expanding family of targets for cancer immunotherapy. Immunol. Rev. 188 22-32 (2002).

16. Apostolopoulos, V., Pietersz, G. A. \& McKenzie, I. F. MUC1 and breast cancer. Curr. Opin. Mol. Ther. 1, 98-103 (1999)

17. Disis, M. et al. Generation of T-cell immunity to the HER-2/neu protein after active immunization with HER-2/neu peptidebased vaccines. J. Clin. Oncol. 20, 2624-2632 (2002). The authors show that a vaccine based on HER2/NEU peptides that contain potential epitopes for $\mathrm{T}$ helper $(T$, cells, can elicit in patients with cancer, immunity $\left(T_{H}\right)$ cells, can elicit in patients with cancer, immunity provoke endogenous immune responses that lead to provoke endogeno
epitope spreading.
18. Chomez, P. et al. An overview of the MAGE gene family with the identification of all human members of the family. Cancer Res. 61, 5544-5551 (2001).

19. Tanaka, Y., Amos, K. D. Fleming, T. P. Eberlein, T. J. \& Goedegebuure, P. S. Mammaglobin-A is a tumorassociated antigen in human breast carcinoma. Surgery 133, 74-80 (2003).

20. Schlom, J. et al. Strategies for the development of recombinant vaccines for the immunotherapy of breast cancer. Breast Cancer Res. Treat. 38, 27-39 (1996).

21. Kao, H. et al. Identification of cyclin B1 as a shared human epithelial tumor-associated antigen recognized by $\mathrm{T}$ cells. J. Exp. Med. 194, 1313-1323 (2001).

This paper defines a cell-cycle regulatory protein cyclin B1 as a target of human $\mathrm{CD}^{+} \mathrm{T}$-cell responses. Cyclin B1 is aberrantly expressed by many cancers.

22. Jager, D. et al. Cancer-testis antigens and ING1 tumer suppressor gene product are breast cancer antigens: characterization of tissue-specific ING1 transcripts and a homologue gene. Cancer Res. 59, 6197-6204 (1999).

23. Nestle, F. O. Vaccines and melanoma. Clin. Exp. Dermatol. 27, 597-601 (2002).

24. Srivastava, P. K. Immunotherapy of human cancer: lessons from mice. Nature Immunol. 1, 363-366 (2000).

25. Gendler, S. J. \& Mukherjee, P. Spontaneous adenocarcinoma mouse models for immunotherapy. Trends Mol. Med. 7, 471-475 (2001).

26. Greiner, J. W., Zeytin, H., Anver, M. R. \& Schlom, J. Vaccine based therapy directed against carcinoembryonic antigen demonstrates antitumor activity on spontaneous intestinal tumours in the absence of autoimmunity. Cancer Res. 62, 6944-6951 (2002).

This paper shows the efficacy of a carcinoembryonic antigen (CEA) vaccine against spontaneous intestina tumours in genetically predisposed mice. The vaccin generated a strong anti-CEA response that reduced the tumour incidence and increased overall survival without causing autoimmunity.

27. Meng, W. S. et al. $\alpha$-Fetoprotein-specific tumor immunity induced by plasmid prime-adenovirus boost genetic vaccination. Cancer Res. 61, 8782-8786 (2001). 
28. Ranieri, E. et al. Dendritic cell/peptide cancer vaccines: clinical responsiveness and epitope spreading. Immunol. Invest. 29, 121-125 (2000).

29. Butterfield, L. H. et al. Determinant spreading associated with clinical response in dendritic cell-based immunotherapy for malignant melanoma. Clin. Cancer Res. 9, 998-1008 (2003).

30. Salgaller, M. L. \& Lodge, P. A. Use of cellular and cytokine adjuvants in the immunotherapy of cancer. J. Surg. Oncol. 68, 122-138 (1998)

31. Medzhitov, R. CpG DNA: security code for host defense. Nature Immunol. 2, 15-16 (2001).

32. Krug, A. et al. CpG-A oligonucleotides induce a monocytederived dendritic cell-like phenotype that preferentially activates CD8 T cells. J. Immunol. 170, 3468-3477 (2003).

33. Janeway, C. A., Jr \& Medzhitov, R. Lipoproteins take their toll on the host. Curr. Biol. 9, R879-R882 (1999).

34. Sieling, P. A., Chung, W., Duong, B. T., Godowski, P. J. \& Modlin, R. L. Toll-like receptor 2 ligands as adjuvants for Modin, R. L. Toll-like receptor 2 ligands as adjuvants for

35. Kovacsovics-Bankowski, M. \& Rock, K. L. A phagosome to-cytosol pathway for exogenous antigens presented on MHC class I molecules. Science 267, 243-246 (1995).

36. Gupta, R. K., Singh, M. \& O'Hagan, D. T. Poly(lactide-coglycolide) microparticles for the development of single-dose controlled-release vaccines. Adv. Drug Deliv. Rev. 32, 225-246 (1998).

37. Lo-Man, R. et al. A recombinant virus-like particle system derived from parvovirus as an efficient antigen carrier to elicit a polarized $\mathrm{T}_{H} 1$ immune response without adjuvant. Eur. J. Immunol. 28, 1401-1407 (1998).

38. Takahashi, H., Takeshita, T., Morein, B., Putney, S., Germain, R. N. \& Berzofsky, J. A. Induction of CD8 cytotoxic $\mathrm{T}$ cells by immunization with purified HIV-1 envelope protein in ISCOMs. Nature 344, 873-875 (1990).

39. Srivastava, P. Interaction of heat shock proteins with peptides and antigen presenting cells: chaperoning of the innate and adaptive immune responses. Annu. Rev. Immunol. 20, 395-425 (2002).

40. Eriksson, K. \& Holmgren, J. Recent advances in mucosal vaccines and adjuvants. Curr. Opin. Immunol. 14, 666-672 (2002)

41. Cook, D. N. et al. CCR6 mediates dendritic cell localization, lymphocyte homeostasis, and immune responses in mucosal tissue. Immunity 12, 495-503 (2000).

42. Csencsits, K. L., Jutila, M. A. \& Pascual, D. W. Mucosal addressin expression and binding-interactions with naive lymphocytes vary among the cranial, oral, and nasal-
associated lymphoid tissues. Eur. J. Immunol. 32, 3029-3039 (2002).

43. Williamson, E., Bilsborough, J. M. \& Viney, J. L. Regulation of mucosal dendritic cell function by receptor activator of NF-KB (RANK)/RANK ligand interactions: impact on tolerance induction. J. Immunol. 169, 3606-3612 (2002).

44. Medzhitov, R. \& Janeway, C., Jr. The Toll receptor family and microbial recognition. Trends Microbiol. 8, 452-456 (2000).

45. Mosmann, T. R. \& Coffman, R. L. TH 1 and $T_{H} 2$ cells: different patterns of lymphokine secretion lead to different functional properties. Annu. Rev. Immunol. 7, 145-173 (1989).

46. Tatsumi, T. et al. Disease-associated bias in Thelper type 1 $\left(T_{H} 1\right) / T_{H} 2 C D 4^{+} T$ cell responses against MAGE- 6 in HLADRB10401+ patients with renal cell carcinoma or melanoma. J. Exp. Med. 196, 619-628 (2002)

47. Davis, T. A., Maloney, D. G., Czerwinski, D. K., Liles, T. M. \& Levy, R. Anti-idiotype antibodies can induce long-term complete remissions in non-Hodgkin's lymphoma withou eradicating the malignant clone. Blood $\mathbf{9 2}, 1184-1190$ eradicating
(1998).

48. Vogel, C. et al. First-line, single-agent Herceptin(trastuzumab) in metastatic breast cance : a preliminary report. Eur. J. Cancer 37, S25-S29 (2001)

49. Riethmuller, G. et al. Randomised trial of monoclonal antibody for adjuvant therapy of resected Dukes' C colorectal carcinoma. German Cancer Aid 17-1A Study Group. Lancet 343, 1177-1183 (1994).

50. Hsu, F. J. et al. Tumor-specific idiotype vaccines in the treatment of patients with B-cell lymphoma - long-term treatment of patients with B-cell lymphoma - long-term
results of a clinical trial. Blood 89, 3129-3135 (1997).

51. Livingston, P. O. et al. Vaccines containing purified GM2 ganglioside elicit GM2 antibodies in melanoma patients. Proc. Natl Acad. Sci. USA 84, 2911-2915 (1987).

52. Parmiani, G. et al. Cancer immunotherapy with peptidebased vaccines: what have we achieved? Where are we going? J. Natl Cancer Inst. 94, 805-818 (2002).

53. Ahmed, R. \& Gray, D. Immunological memory and protective immunity: understanding their relation. Science 272, 54-60 (1996).

54. Zinkernagel, R. M. On differences between immunity and immunological memory. Curr. Opin. Immunol. 14, 523-536 (2002).
55. Sallusto, F., Langenkamp, A., Geginat, J. \& Lanzavecchia, A. Functional subsets of memory T cells identified by CCR7 expression. Curr. Top. Microbiol. Immunol. 251, 167-171 (2000).

56. Harrington, L. E., Galvan, M., Baum, L. G., Altman, J. D. \& Ahmed, R. Differentiating between memory and effector CD8 T cells by altered expression of cell surface O-glycans J. Exp. Med. 191, 1241-1246 (2000).

57. Fernando, G. J., Khammanivong, V., Leggatt, G. R. Liu, W. J. \& Frazer, I. H. The number of long-lasting functional memory $\mathrm{CD} 8^{+} \mathrm{T}$ cells generated depends on the nature of the initial nonspecific stimulation. Eur. J. Immunol 32, 1541-1549 (2002)

58. Xiang, R., Lode, H. N., Gillies, S. D. \& Reisfeld, R. A. T cell memory against colon carcinoma is long-lived in the absence of antigen. J. Immunol. 163, 3676-3683 (1999).

59. Mortarini, R. et al. Peripheral burst of tumor-specific cytotoxic T lymphocytes and infiltration of metastatic lesions by memory $C D 8^{+} T$ cells in melanoma patients receiving by memory CD8 ${ }^{+} T$ cells in melanoma patients receling

60. Feuerer, M. et al. Therapy of human tumors in NOD/SCID mice with patient-derived reactivated memory $T$ cells from bone marrow. Nature Med. 7, 452-458 (2001).

61. Zajac, A. J., Murali-Krishna, K., Blattman, J. N. \& Ahmed, R. Therapeutic vaccination against chronic viral infection: the importance of cooperation between $\mathrm{CD} 4^{+}$and $\mathrm{CD} 8^{+} \mathrm{T}$ cells. Curr. Opin. Immunol. 10, 444-449 (1998).

62. van der Burg, S. H. et al. Long lasting p53-specific T cell memory responses in the absence of anti-p53 antibodies in patients with resected primary colorectal cancer. Eur. J. Immunol. 31, 146-155 (2001).

63. Gao, F. G. et al. Antigen-specific CD4 ${ }^{+}$T-cell help is required to activate a memory $\mathrm{CD}^{+} \mathrm{T}$ cell to a fully functional tumor killer cell. Cancer Res. 62, 6438-6441 (2002).

64. Wherry, E. J. et al. Lineage relationship and protective immunity of memory CD8 T cell subsets. Nature Immunol. 4, 225-234 (2003).

65. Elrefaei, M., Blank, K. J. \& Murasko, D. M. Decreased IL-2, IFN- $\gamma$, and IL-10 production by aged mice during the acute phase of E55+ retrovirus infection. Virology 299, 8-19 (2002).

66. Kapasi, Z. F., Murali-Krishna, K., McRae, M. L. \& Ahmed, R. Defective generation but normal maintenance of memory T cells in old mice. Eur. J. Immunol. 32, 1567-1573 (2002).

67. Khare, V., Sodhi, A. \& Singh, S. M. Age-dependent alterations in the tumoricidal functions of tumor-associated macrophages. Tumour Biol. 20, 30-43 (1999).

68. Lu, Y. F. \& Cerny, J. Repertoire of antibody response in bone marrow and the memory response are differentially affected in aging mice. J. Immunol. 169, 4920-4927 (2002).

69. Garcia, G. G. \& Miller, R. A. Age-dependent defects in TCRtriggered cytoskeletal rearrangement in $\mathrm{CD} 4^{+} \mathrm{T}$ cells. $\mathrm{J}$ Immunol. 169, 5021-5027 (2002).

70. Miller, R. A. \& Chrisp, C. T cell subset patterns that predict resistance to spontaneous lymphoma, mammary adenocarcinoma, and fibrosarcoma in mice. J. Immunol. 169, 1619-1625 (2002).

This and other papers by the first author focus on age-induced changes in the immune system that contribute to carcinogenesis and could affect the success of cancer vaccines.

71. Provinciali, M., Smorlesi, A., Donnini, A., Bartozzi, B. \& Amici, A. Low effectiveness of DNA vaccination against HER-2/neu in ageing. Vaccine 21, 843-848 (2003).

This paper shows a clear difference in the response of young versus old mice to a HER2/NEU-containing cancer vaccine and the difference in the immuneeffector mechanisms that are generated.

72. Bansal-Pakala, P. \& Croft, M. Defective T cell priming associated with aging can be rescued by signaling through 4-1BB (CD137). J. Immunol. 169, 5005-5009 (2002).

73. Egen, J. G., Kuhns, M. S. \& Allison, J. P. CTLA-4: new insights into its biological function and use in tumor immunotherapy. Nature Immunol. 3, 611-618 (2002).

74. Maletto, B., Ropolo, A., Moron, V. \& Pistoresi-Palencia, M. C. CpG-DNA stimulates cellular and humoral immunity and promotes $T_{1} 1$ differentiation in aged BALB/c mice. promotes $T_{H}$ differentiation in aged

75. Geiger J. D. et al. Vaccination of pediatric solid tumor patients with tumor lysate-pulsed dendritic cells can expand specific T cells and mediate tumor regression. Cancer Res. 61, 8513-8519 (2001)

76. Dunn, G. P., Bruce, A. T., Ikeda, H., Old, L. J. \& Schreiber, R. D. Cancer immunoediting: from immunosurveillance to tumor escape. Nature Immunol. 3, 991-998 (2002)

77. Ishida, T., Oyama, T., Carbone, D. P. \& Gabrilovich, D. I. Defective function of Langerhans cells in tumor-bearing animals is the result of defective maturation from hemopoietic progenitors. J. Immunol. 161, 4842-4851 (1998).
78. Shurin, G. V. et al. Human prostate cancer blocks the generation of dendritic cells from $\mathrm{CD} 34^{+}$hematopoietic progenitors. Eur. Urol. 39, S37-S40 (2001):

79. Mizoguchi, H. et al. Alterations in signal transduction molecules in Tlymphocytes from tumor-bearing mice. Science 258, 1795-1798 (1992).

The original paper that describes tumour-induced suppression of $T$ cells in mice with tumours.

80. Finke, J., Ferrone, S., Frey, A., Mufson, A. \& Ochoa, A. Where have all the T cells gone? Mechanisms of immune evasion by tumors. Immunol. Today. 20, 158-160 (1999).

81. Garcia-Hernandez, M. L., Hernandez-Pando, R., Gariglio, P. \& Berumen, J. Interleukin-10 promotes B16-melanoma growth by inhibition of macrophage functions and induction of tumour and vascular cell proliferation. Immunol. 105, 231-243 (2002)

82. Lin, C. M., Wang, F. H. \& Lee, P. K. Activated human CD4+ T cells induced by dendritic cell stimulation are most sensitive to transforming growth factor- $\beta$ : implications for dendritic cell immunization against cancer. Clin. Immunol. 102, 96-105 (2002)

83. Skinnider, B. F. \& Mak, T. W. The role of cytokines in classical Hodgkin lymphoma. Blood 99, 4283-4297 (2002).

84. Friberg, M. et al. Indoleamine 2,3-dioxygenase contributes to tumor cell evasion of T cell-mediated rejection. Int. J. Cancer 101, 151-155 (2002)

85. Iwai, Y. et al. Involvement of PD-L1 on tumor cells in the escape from host immune system and tumor immunotherapy by PD-L1 blockade. Proc. Natl Acad. Sci. USA 99, 12293-12297 (2002).

86. Schmielau, J. \& Finn, O. J. Activated granulocytes and granulocyte-derived hydrogen peroxide are the underlying mechanism of suppression of T-cell function in advanced cancer patients. Cancer Res. 61, 4756-4760 (2001).

87. Ahlers, J. D. et al. A push-pull approach to maximize vaccine efficacy: abrogating suppression with an IL-13 inhibitor while augmenting help with granulocyte/ macrophage colony-stimulating factor and CD4OL. Proc. Natl Acad. Sci. USA 99, 13020-13025 (2002).

88. Gabrilovich, D. I., Ishida, T., Nadaf, S., Ohm, J. E. \& Carbone, D. P. Antibodies to vascular endothelial growth factor enhance the efficacy of cancer immunotherapy by improving endogenous dendritic cell function. Clin. Cancer Res. 5, 2963-2970 (1999).

89. Meidenbauer, N., Gooding, W., Spitler, L., Harris, D. \& Whiteside, T. L. Recovery of $\zeta$-chain expression and changes in spontaneous IL-10 production after PSA-based vaccines in patients with prostate cancer. Br. J. Cancer $\mathbf{8 6}$, 168-178 (2002).

90. Liyanage, U. K. et al. Prevalence of regulatory $T$ cells is increased in peripheral blood and tumor microenvironment of patients with pancreas or breast adenocarcinoma. J. Immunol. 169, 2756-2761 (2002).

91. Piccirillo, C. A. \& Shevach, E. M. Cutting edge: control of $\mathrm{CD} 8^{+} \mathrm{T}$ cell activation by $\mathrm{CD} 4^{+} \mathrm{CD} 25^{+}$immunoregulatory cells. J. Immunol. 167, 1137-1140 (2001).

92. Golgher, D., Jones, E., Powrie, F., Elliott, T. \& Gallimore, A. Depletion of $\mathrm{CD} 25^{+}$regulatory cells uncovers immune responses to shared murine tumor rejection antigens. Eur. $J$. Immunol. 32, 3267-3275 (2002).

93. Mitchell, M. S. et al. Active specific immunotherapy for melanoma: phase I trial of allogeneic lysates and a novel adjuvant. Cancer Res. 48, 5883-5893 (1988).

94. Morton, D. L. et al. Prolonged survival of patients receiving active immunotherapy with Canvaxin therapeutic polyvalent vaccine after complete resection of melanoma metastatic to vaccine after complete resection of melanoma metastatic
regional lymph nodes. Ann. Surg. 236, 438-449 (2002).

95. Bystryn, J. C. et al. Immunogenicity of a polyvalent melanom Bystryn, J. C. et al. Immunogenicity of a polyvalent melanoma
antigen vaccine in humans. Cancer 61, 1065-1070 (1988).

96. Miller, K. et al. Improved survival of patients with melanoma with an antibody response to immunization to a polyvalent melanoma vaccine. Cancer 75, 495-502 (1995).

97. Mitchell, M. S. Perspective on allogeneic melanoma lysates in active specific immunotherapy. Semin. Oncol. 25 , 623-635 (1998).

98. Berd, D., Sato, T., Cohn, H., Maguire, H. C., Jr \& Mastrangelo, M. J. Treatment of metastatic melanoma with autologous, hapten-modified melanoma vaccine: regression of pulmonary metastases. Int. J. Cancer 94, 531-539 (2001).

99. Mach, N. \& Dranoff, G. Cytokine-secreting tumor cell vaccines. Curr. Opin. Immunol. 12, 571-575 (2000).

100. Belli, F. et al. Vaccination of metastatic melanoma patients with autologous tumor-derived heat shock protein gp96peptide complexes: clinical and immunologic findings. J. Clin. Oncol. 20, 4169-4180 (2002).

101. Salgia, R. et al. Vaccination with irradiated autologous tumor cells engineered to secrete granulocyte-macrophage colony-stimulating factor augments antitumor immunity in some patients with metastatic non-small-cell lung carcinoma. J. Clin. Oncol. 21, 624-630 (2003). 
102. Nestle, F. O., Banchereau, J. \& Hart, D. Dendritic cells: on the move from bench to bedside. Nature Med. $\mathbf{7}$, 761-765 (2001).

103. Celluzzi, C. M. \& Falo, L. D., Jr. Physical interaction between dendritic cells and tumor cells results in an immunogen that induces protective and therapeutic tumor rejection.
J. Immunol. 160, 3081-3085 (1998).

104. Nouri-Shirazi, M. et al. Dendritic cells capture killed tumor cells and present their antigens to elicit tumor-specific immune responses. J. Immunol. 165, 3797-3803 (2000).

105. Chang, A. E. et al. A phase I trial of tumor lysate-pulsed dendritic cells in the treatment of advanced cancer. Clin. Cancer Res. 8, 1021-1032 (2002)

106. Heiser, A. et al. Induction of polyclonal prostate cancerspecific CTL using dendritic cells transfected with amplified tumor RNA. J. Immunol. 166, 2953-2960 (2001).

107. Nair, S. K. et al. Induction of tumor-specific cytotoxic T lymphocytes in cancer patients by autologous tumor RNAtransfected dendritic cells. Ann. Surg. 235, 540-549 (2002).

108. Condon, C., Watkins, S. C., Celluzzi, C. M., Thompson, K. Falo, L. D., Jr. DNA-based immunization by in vivo transfection of dendritic cells. Nature Med. 2, 1122-1128 (1996)

109. Whiteside, T. L., Gambotto, A., Albers, A., Stanson, J. \& Cohen, E. P. Human tumor-derived genomic DNA transduced into a recipient cell induces tumor-specific immune responses ex vivo. Proc. Natl Acad. Sci. USA 99, 9415-9420 (2002).

110. Heiser, A. et al. Autologous dendritic cells transfected with prostate-specific antigen RNA stimulate CTL responses against metastatic prostate tumors. J. Clin. Invest. 109, 409-417 (2002).

111. Goydos, J. S., Elder, E. Whiteside, T. L., Finn, O.J. \& Lotze, M. T. A phase I trial of a synthetic mucin peptide vaccine. Induction of specific immune reactivity in patients with adenocarcinoma. J. Surg. Res. 63, 298-304 (1996).

112. Khleif, S. N. et al. A phase I vaccine trial with peptides reflecting ras oncogene mutations of solid tumors. J. Immunother. 22, 155-165 (1999).

113. Massaia, M. et al. Idiotype vaccination in human myeloma: generation of tumor-specific immune responses after highdose chemotherapy. Blood 94, 673-683 (1999).

114. van Driel, W. J. et al. Vaccination with HPV16 peptides of patients with advanced cervical carcinoma: clinical evaluation of a phase I-II trial. Eur. J. Cancer 35, 946-952 (1999).

115. Brossart, P. et al. Induction of cytotoxic T-lymphocyte responses in vivo after vaccinations with peptide-pulsed dendritic cells. Blood 96, 3102-3108 (2000).

116. Marshall, J. L. et al. Phase I study in advanced cancer patients of a diversified prime-and-boost vaccination protocol using recombinant vaccinia virus and recombinant nonreplicating avipox virus to elicit anti-carcinoembryonic antigen immune responses. J. Clin. Oncol. 18, 3964-3973 antigen
(2000).

117. Banchereau, J. et al. Immune and clinical responses in patients with metastatic melanoma to $\mathrm{CD} 34^{+}$progenitorderived dendritic cell vaccine. Cancer Res. 61, 6451-6458 (2001)

118. Schuler-Thurner, B. et al. Rapid induction of tumor-specific type $1 \mathrm{~T}$ helper cells in metastatic melanoma patients by vaccination with mature, cryopreserved, peptide-loaded monocyte-derived dendritic cells. J. Exp. Med. 195 1279-1288 (2002).

119. Knutson, K. L. Schiffman, K. \& Disis, M. L. Immunization with a HER-2/neu helper peptide vaccine generates HER2/neu CD8 T-cell immunity in cancer patients. J. Clin. Invest. $107,477-484$ (2001).

120. van der Burg, S. H. et al. Induction of p53-specific immune responses in colorectal cancer patients receiving a recombinant ALVAC-p53 candidate vaccine. Clin. Cancer Res. 8, 1019-1027 (2002)

121. Marchand, M. et al. Immunisation of metastatic cancer patients with MAGE-3 protein combined with adjuvan SBAS-2: a clinical report. Eur. J. Cancer 39, 70-77 (2003).

122. Finn, O. J. \& Forni, G. Prophylactic cancer vaccines. Curr. Opin. Immunol. 14, 172-177 (2002).

123. Schultz, J. Success of vaccine offers promise of cervical cancer prevention. J. Nat/ Cancer Inst. 95, 102-104 (2003).

124. Welters, M. J. et al. Frequent display of human papillomavirus type 16 E6-specific memory T-helper cells in the healthy population as witness of previous viral encounte Cancer Res. 63, 636-641 (2003).

125. Plummer, M. \& Franceschi, S. Strategies for HPV prevention. Virus Res. 89, 285-293 (2002).
126. Huang, K. \& Lin, S. Nationwide vaccination: a success story in Taiwan. Vaccine 18, S35-S38 (2000).

127. Viviani, S. et al. Hepatitis B vaccination in infancy in The Gambia: protection against carriage at 9 years of age. Vaccine 17, 2946-2950 (1999).

128. Lollini, P. L. et al. Immunoprevention of colorectal cancer: a future possibility? Gastroenterol. Clin. North Am. $\mathbf{3 1}$, 1001-1014 (2002).

129. Lollini, P. L. \& Forni, G. Antitumor vaccines: is it possible to prevent a tumor? Cancer Immunol. Immunother. 51, 409-416 (2002)

130. Muderspach, L. et al. A phase I trial of a human papillomavirus (HPV) peptide vaccine for women with high-grade cervical and vulvar intraepithelial neoplasia who are HPV 16 positive. Clin. Cancer Res. 6, 3406-3416 (2000).

131. Finn, O. J. et al. MUC-1 epithelial tumor mucin-based immunity and cancer vaccines. Immunol. Rev. 145, 61-89 (1995).

132. Domenech, N., Henderson, R. A. \& Finn, O. J. Identification of an HLA-A11-restricted epitope from the tandem repeat domain of the epithelial tumor antigen mucin. J. Immunol. 155, 4766-4774 (1995)

133. Hiltbold, E. M., Ciborowski, P. \& Finn, O. J. Naturally processed class II epitope from the tumor antigen MUC1 primes human $\mathrm{CD}^{+}{ }^{+} \mathrm{T}$ cells. Cancer Res. 58, 5066-5070 (1998).

134. Hiltbold, E. M., Alter, M. D., Ciborowski, P. \& Finn, O. J. Presentation of MUC1 tumor antigen by class I MHC and protein taken up by dendritic cells. Cell. Immunol. 194 143-149 (1999).

135. Vlad, A. M. et al. Complex carbohydrates are not removed during processing of glycoproteins by dendritic cells: processing of tumor antigen MUC1 glycopeptides for presentation to major histocompatibility complex class IIrestricted T cells. J. Exp. Med. 196, 1435-1446 (2002). An important observation that glycoprotein tumour antigens might be a source of glycopeptides that are processed and presented by MHC class II molecules to glycopeptide-specific $T_{H}$ cells

136. Apostolopoulos, V., Karanikas, V., Haurum, J.S. \& McKenzie, I. F. Induction of HLA-A2-restricted CTLs to the mucin 1 human breast cancer antigen. J. Immunol. 159. 5211-5218 (1997)

137. Brossart, P. et al. Identification of HLA-A2-restricted T-cell epitopes derived from the MUC1 tumor antigen for broadly applicable vaccine therapies. Blood 93, 4309-4317 (1999).

138. Lees, C. J. et al. Immunotherapy with mannan-MUC1 and IL-12 in MUC1 transgenic mice. Vaccine 19, 158-162 (2000).

139. Mukherjee, P. et al. Mice with spontaneous pancreatic cancer naturally develop MUC-1-specific CTLs that eradicate tumors when adoptively transferred. J. Immunol. 165, 3451-3460 (2000).

140. Pecher, G. \& Finn O.J. Induction of cellular immunity in chimpanzees to human tumor-associated antigen mucin by vaccination with MUC-1 CDNA-transfected Epstein-Barr virus-immortalized autologous B cells. Proc. Nat/ Acad. Sci. USA 93, 1699-1704 (1996).

141. Barratt-Boyes, S. M., Vlad, A. \& Finn, O. J. Immunization of chimpanzees with tumor antigen MUC1 mucin tandem repeat peptide elicits both helper and cytotoxic T-cell responses. Clin. Cancer Res. 5, 1918-1924 (1999).

142. Carr-Brendel, V. et al. Immunity to murine breast cancer cells modified to express MUC-1, a human breast cancer antigen, in transgenic mice tolerant to human MUC-1. Cancer Res. 60, 2435-2443 (2000).

143. Grosenbach, D. W., Barrientos, J. C., Schlom, J. \& Hodge, J. W. Synergy of vaccine strategies to amplify antigen-specific immune responses and antitumor effects. Cancer Res. 61, 4497-4505 (2001).

144. Xiang, R. et al. Protective immunity against human carcinoembryonic antigen (CEA) induced by an oral DNA vaccine in CEA-transgenic mice. Clin. Cancer Res. 7 , S856-S864 (2001).

145. Cole, D. J. et al. Phase I study of recombinant CEA vaccinia virus vaccine with post vaccination CEA peptide challenge. Hum. Gene Ther. 7, 1381-1394 (1996).

146. Nanni, P. et al. Combined allogeneic tumor cell vaccination and systemic interleukin 12 prevents mammary carcinogenesis in HER-2/neu transgenic mice. J. Exp. Med. 194, 1195-1205 (2001)

147. Timmerman, J. M. \& Levy, R. The history of the development of vaccines for the treatment of lymphoma. Clin. Lymphoma 1, 129-139; discussion 140 (2000).
148. Hruban, R. H. et al. Pancreatic intraepithelial neoplasia: a new nomenclature and classification system for pancreatic duct lesions. Am. J. Surg. Pathol. 25, 579-586 (2001).

149. Nelson, W. G. et al. Preneoplastic prostate lesions: an opportunity for prostate cancer prevention. Ann. NY Acad. Sci. 952, 135-144 (2001).

150. Burgart, L. J. Colorectal polyps and other precursor lesions. Need for an expanded view. Gastroenterol. Clin. North Am. 31, 959-970 (2002).

151. Pfau, P. \& Chak, A. Detection of preinvasive cancer cells: early-warning changes in precancerous epithelial cells can now be spotted in situ and endoscopic detection of dysplasia in patients with Barrett's esophagus using lightscattered spectroscopy. Gastrointest. Endosc. 54, 414-416 (2001)

152. Kauff, N. D. et al. Risk-reducing salpingo-oophorectomy in women with a BRCA1 or BRCA2 mutation. N. Engl. J. Med. 346, 1609-1615 (2002)

153. Meijers-Heijboer, H. et al. Breast cancer after prophylactic bilateral mastectomy in women with a BRCA1 or BRCA2 mutation. N. Engl. J. Med. 345, 159-164 (2001).

154. Rebbeck, T. R. et al. Prophylactic oophorectomy in carriers of BRCA1 or BRCA2 mutations. N. Engl. J. Med. 346 1616-1622 (2002).

155. Hartmann, L. C. et al. Efficacy of bilateral prophylactic mastectomy in women with a family history of breast cancer. N. Engl. J. Med. 340, 77-84 (1999).

156. Pennisi, V. R. \& Capozzi, A. Subcutaneous mastectomy data: a final statistical analysis of 1500 patients. Aesthetic data: a final statistical analysis of

157. Stefanek, M., Hartmann, L. \& Nelson, W. Risk-reduction mastectomy: clinical issues and research needs. J. Natl Cancer Inst. 93, 1297-1306 (2001).

158. Disis, M. L. et al. Flt3 ligand as a vaccine adjuvant in association with HER-2/neu peptide-based vaccines in patients with HER-2/neu-overexpressing cancers. Blood $\mathbf{9 9}$ 2845-2850 (2002).

159. Whitcomb, D. C. Genetic predispositions to acute and chronic pancreatitis. Med. Clin. North Am. 84, 531-547 (2000).

160. Lowenfels, A. B. et al. Hereditary pancreatitis and the risk of pancreatic cancer. International Hereditary Pancreatitis Study Group. J. Nat/ Cancer Inst. 89, 442-446 (1997).

161. Lowenfels, A. B., Maisonneuve, P., Whitcomb, D. C., Lerch, M. M. \& DiMagno, E. P. Cigarette smoking as a risk factor for pancreatic cancer in patients with hereditary pancreatitis. JAMA 286, 169-170 (2001).

162. Kinzler, K. W. \& Vogelstein, B. Lessons from hereditary colorectal cancer. Cell 87, 159-170 (1996).

163. Vavasseur, F. et al. O-glycan biosynthesis in human colorectal adenoma cells during progression to cancer. Eur. J. Biochem. 222, 415-424 (1994).

164. Li, A. et al. Comparative study for histology, proliferative activity, glycoproteins, and p53 protein between old and recent colorectal adenomas in Japan. Cancer Lett. 170 45-52 (2001).

Acknowledgements

I thank former and present members of my laboratory, whose work has helped shaped my ideas. I also thank the National Institutes of Health, the American Cancer Society, the Susan G. Komen Foundation, the Nathan Arenson Fund for Pancreatic Cancer Research, and the Bob and Coleen Woeber Fund for Breast Cancer Research for support.

\section{(2) Online links}

\section{DATABASES}

The following terms in this article are linked online to: LocusLink: http://www.ncbi.nlm.nih.gov/LocusLink 4-1BB | CTLA4 | cyclin B1 | GM-CSF | HER2 | IL-2 | IL-4 | IL-10 | IL-12 | IL-13 | MAGE3 | mucin 1 | TGF- $\beta$ Entrez: http://www.ncbi.nlm.nih.gov/entrez HBV |HPV16

\section{FURTHER INFORMATION}

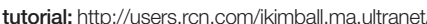
BiologyPages/NNaccines.htm

Cancer Research Institute: http://www.cancerresearch.org/ cancervaccines2000/cv2000index.htm

Therapeutic cancer vaccines: http://www.medscape.com/ viewprogram/2012

National Cancer Institute: http://www.cancer.gov/BenchMarks/

Access to this interactive links box is free online. 